\title{
Pattern of hanging cases brought for autopsy at a tertiary care centre in Central India
}

\author{
Avinash H. Waghmode \\ Assistant Professor, Dept. of Forensic Medicine, BKL Walawalkar Rural Medical College, Chiplun, Ratnagiri, Maharashtra, \\ India
}

*Corresponding Author:

Email: avinashw4@gmail.com

\begin{abstract}
Introduction: This study was the retrospective study carried out in the Department of Forensic medicine and Toxicology at a Tertiary Care Centre during the period June 2016 to June 2017. All the cases with alleged history of hanging were included in this study. In the present study 31 to 40 year was the most commonly involved age group followed by 51-60 years and 41-50 years in which male outnumbered the female. Complete hanging was seen in $75 \%$ deaths. Nylon rope was the most commonly used material for hanging. Evidence of salivary stains around the angle of mouth was present in $25 \%$ of the cases. In $87.5 \%$ of cases the ligature mark was present above the level of thyroid cartilage. The most common reason for hanging deaths was the financial problems (75.83\%). The incidence of hanging was more common in Married people than unmarried people.
\end{abstract}

Keywords: Hanging, Autopsy, Suicide, Ligature material.

\section{Introduction}

Hanging is the form of violent mechanical asphyxial death. It is caused by constriction of neck by suspending the body and force of constriction is either the weight of the body or weight of the head. ${ }^{1}$ It is one of the leading causes of death in the world accounting more than a million deaths annually. ${ }^{2}$ It is one of the most common method used by victim for committing suicide. Among the young adults the incidence of hanging is going on increasing. ${ }^{3}$

Slight force is enough for causing death rather than whole weight of the body. In case of partial hanging only the head and chest are off the ground, with partial suspension of the body and the toes or feet touching the ground, or body being in lying down position, kneeling down position or acquire any posture. ${ }^{4}$ Present study is an attempt to study demographic pattern including age and gender of violent asphyxial deaths in case of hanging.

\section{Materials and Methods}

This retrospective study was conducted during the period from June 2016 to June 2017. A total of 980 autopsies were conducted of which suicidal hanging contributed to 120 cases. All the autopsies had been performed in the department of Forensic Medicine and Toxicology in Tertiary Care Centre situated in Central India. Information regarding age, sex, residence, marital status, date of death, reasons of suicide, and all other relevant information about the case had been collected from the accompanying police papers and detail history from the relatives of the victim. The findings were recorded and analysis was done to find out age and sex distribution, type of hanging, level of ligature mark, type of ligature material used and reasons of suicide etc. The data was studied statistically using percentage and ratio analysis and finally inferences were made. This study was carried out by taking permission from the Institutional Ethical Committee.

Inclusion Criteria: All the cases with alleged history of hanging are included in this study

Exclusion Criteria: All the victims who died of violent asphyxial deaths other than hanging.

Statistical Analysis: The study was analysed by using percentage and ratio analysis.

\section{Observations and Results}

Table 1: Distribution of hanging cases according to age and sex

\begin{tabular}{|l|c|c|c|c|}
\hline \multirow{2}{*}{ Age in years } & \multicolumn{2}{|c|}{ No of Cases } & \multirow{2}{*}{ Total } & \multirow{2}{*}{ Percentage } \\
\cline { 2 - 3 } & Males & Females & & \\
\hline $0-10$ & $00(00 \%)$ & $00(00 \%)$ & 00 & $00 \%$ \\
\hline $11-20$ & $02(1.67 \%)$ & $06(5 \%)$ & 08 & $6.67 \%$ \\
\hline $21-30$ & $15(12.5 \%)$ & $05(4.17 \%)$ & 20 & $16.67 \%$ \\
\hline $31-40$ & $35(29.67 \%)$ & $05(4.17 \%)$ & 40 & $33.33 \%$ \\
\hline $41-50$ & $19(15.83 \%)$ & $02(1.67 \%)$ & 21 & $17.5 \%$ \\
\hline $51-60$ & $22(18.33 \%)$ & $00(00 \%)$ & 22 & $18.33 \%$ \\
\hline $61-80$ & $08(6.67 \%)$ & $00(00 \%)$ & 08 & $6.67 \%$ \\
\hline $81-90$ & $01(0.83 \%)$ & $00(00 \%)$ & 01 & $0.83 \%$ \\
\hline$>90$ & $00(00 \%)$ & $00(00 \%)$ & 00 & $00 \%$ \\
\hline Total & $102(85 \%)$ & $18(15 \%)$ & 120 & $100 \%$ \\
\hline
\end{tabular}


(Table 1) shows distribution of hanging cases according to Age and Sex. From the Table 1 it is observed that incidence of hanging was more in males than the females. Out of 120 cases, $102(85 \%)$ victims were males and $18(15 \%)$ cases were females. Table 1 also shows that out of 120 cases, age group of 31-40 years was most commonly involved which accounts for $40(33.33 \%)$ cases, followed by 51-60 years 22 $(18.33 \%)$ and $41-50$ years $21(17.5 \%)$ cases.

Table 2: Distribution of cases according to type of hanging

\begin{tabular}{|l|c|c|}
\hline Type of Hanging & Number of cases & Percentage \\
\hline Complete & 90 & $75 \%$ \\
\hline Incomplete & 30 & $25 \%$ \\
\hline Total & 120 & $100 \%$ \\
\hline
\end{tabular}

(Table 2) shows distribution of cases according to type of hanging whether it is complete or incomplete hanging. From the Table 2 it is observed that incidence of complete hanging was seen in $90(75 \%)$ cases and partial hanging was present in $30(25 \%)$ of cases.

Table 3: Distribution of cases with regard the level of ligature mark

\begin{tabular}{|l|c|c|}
\hline $\begin{array}{c}\text { Level of ligature mark } \\
\text { with regard to Thyroid } \\
\text { Cartilage }\end{array}$ & $\begin{array}{c}\text { No of } \\
\text { cases }\end{array}$ & Percentage \\
\hline Below the level & 10 & $8.33 \%$ \\
\hline At the level & 05 & $4.17 \%$ \\
\hline Above the level & 105 & $87.5 \%$ \\
\hline Total & 120 & 100 \\
\hline
\end{tabular}

(Table 3) shows distribution of cases according to the level of ligature mark. In my study ligature mark was found above the thyroid cartilage in $105(87.5 \%)$ cases, below the thyroid cartilage in $10(8.33 \%)$ cases and at the level of thyroid cartilage in $05(4.17 \%)$ cases.

Table 4: Distribution of hanging cases according to presence or absence of salivary stains

\begin{tabular}{|l|c|c|}
\hline Salivary Stains & No. of cases & Percentage \\
\hline Present & 30 & $25 \%$ \\
\hline Absent & 90 & $75 \%$ \\
\hline Total & 120 & $100 \%$ \\
\hline
\end{tabular}

(Table 4) shows distribution of hanging cases according to presence or absence of salivary stains. From the (Table. 4) it is seen that oozing of saliva from the angle of mouth (Salivary stains) which is sign of antemortem hanging is present in $30(25 \%)$ of cases and absent in $90(75 \%)$ of cases.
Table 5: Distribution of cases according to the type of ligature material used

\begin{tabular}{|l|c|c|}
\hline \multicolumn{1}{|c|}{ Ligature } & Number of cases & Percentage \\
\hline Nylon rope & 78 & $65 \%$ \\
\hline Cotton rope & 06 & $5 \%$ \\
\hline Metal Wire & 05 & $4.67 \%$ \\
\hline Cable wire & 02 & $1.67 \%$ \\
\hline Saree & 07 & $5.83 \%$ \\
\hline Dhoti & 06 & $5 \%$ \\
\hline Lungi & 04 & $3.33 \%$ \\
\hline Dupatta & 12 & $10 \%$ \\
\hline Total & 120 & $100 \%$ \\
\hline
\end{tabular}

(Table 5) shows distribution of cases according to the type of ligature material Used. From the Table 5 it is evident that the nylon materials were most commonly used as ligature materials for hanging which constitutes $97(80.83 \%)$ cases. Out of these Nylon rope was used in $78(65 \%)$ cases.

Table 6: Distribution of cases of hanging according to reasons for committing suicide

\begin{tabular}{|l|c|c|}
\hline \multicolumn{1}{|c|}{ Reasons } & $\begin{array}{c}\text { No. of } \\
\text { cases }\end{array}$ & Percentage \\
\hline $\begin{array}{l}\text { Financial problems(Economic } \\
\text { Crisis) }\end{array}$ & 91 & $75.83 \%$ \\
\hline $\begin{array}{l}\text { Family disputes (Quarrel } \\
\text { between couples) }\end{array}$ & 02 & $1.67 \%$ \\
\hline Failure in Examination & 01 & $0.83 \%$ \\
\hline Mental Illness & 03 & $2.5 \%$ \\
\hline Dowry Harassment & 05 & $4.17 \%$ \\
\hline Personal Affairs & 08 & $6.67 \%$ \\
\hline Motive not known & 10 & $8.33 \%$ \\
\hline Total & 120 & $100 \%$ \\
\hline
\end{tabular}

(Table 6) shows distribution of hanging cases according to reasons for committing suicide. In my study, financial problems (Economic Crisis) were the most common reason for committing suicide which was found in $91(75.83 \%)$ cases.

\section{Discussion}

In the present study incidence of hanging was more in males than the females. Out of 120 cases, $102(85 \%)$ victims were males and $18(15 \%)$ cases were females. The age group of 31-40 years was most commonly involved which accounts for $40(33.33 \%)$ cases, followed by 51-60 years $22(18.33 \%)$ and $41-50$ years $21(17.5 \%)$ cases. These findings are in agreement with the study done by AzmakD. ${ }^{5}$

With regard to the type of hanging, evidence of complete hanging was seen in $90(75 \%)$ of cases whereas that of partial hanging was present in $30(25 \%)$ of cases of hanging. These findings are in agreement with the study done by Shaikh MMM et al. ${ }^{6}$

Regarding the level of ligature mark, in 105 $(87.5 \%)$ cases ligature mark is present above the level 
of thyroid cartilage in the present study. Findings of present study are in agreement with studies done by Sarangi $\mathrm{MP}^{7}$ and Nikolic S. et al. ${ }^{8}$

In the present study there was evidence of oozing of saliva from the angle of mouth (Salivary stains) in 30 (25\%) cases. The findings are consistent with those of Ashok Kumar Samanta et al. ${ }^{9}$

With regard to type of ligature material used, Nylon material is the most commonly used ligature material for hanging which constitutes $97(80.83 \%)$ cases. Out of these Nylon Rope is used in most of the cases. i.e in $78(65 \%)$ cases. These findings are also found in the study done by Vijayakumari $\mathrm{N}$ et al. ${ }^{10}$

Regarding the reason for suicide, in the present study the most common reason for suicide by hanging was financial problems (Economic Crisis) which were found in $91(75 \%)$ cases. The result of this study is not consistent with the study done by Vijayakumari $\mathrm{N}$ et al. ${ }^{10}$ As the region in which this study was done is having higher number of Farmer population, financial problems might be most common reason for suicide.

\section{Summary and Conclusion}

Out of 120 cases, $102(85 \%)$ victims were males and $18(15 \%)$ cases were females. Out of 120 cases, age group of 31-40 years was most commonly involved which comprises 40 (33.33\%) cases, followed by 51-60 years $22(18.33 \%)$ cases and $41-50$ years $21(17.5 \%)$ cases. Evidence of complete hanging was seen in $75 \%$ of deaths due to hanging.

The level of ligature mark was above the thyroid cartilage in $105(87.5 \%)$ cases. The oozing of saliva from the angle of mouth (Salivary stains) is present in $30(25 \%)$ cases. Nylon rope was most commonly used ligature material for Hanging in $78(65 \%)$ cases. The most common reason for hanging deaths is the financial problems seen in $91(75.83 \%)$ cases.

\section{References}

1. Kannan K, Mathiharan. Modi's Text Book of Medical Jurisprudence and Toxicology. 24th ed. LexisNexis Publishers. pp. 445-475.

2. Mohanty S, Sagu H, Mohanty MK, Patnaik M. Suicide in India: A four year retrospective study. J Forensic Leg Med. 2007;14(2):185-189.

3. David Gunnell, Olive Benne with, Keith Hawton, Sue Simkin and Nav Kapur. The epidemiology and prevention of suicide by hanging: a systematic review. International Journal of Epidemiology. 2005;34(2):433-442.

4. Reddy. K.S.N., The essentials of Forensic Medicine and Toxicology, Published by k Sugunadevi, 2009. 34rd Edition, p 317.

5. Azmak D. Asphyxial deaths: A Retrospective study and review of the literature. American journal of Forensic Medicine and Pathology. 2006;27(2):134-44.

6. Shaikh MMM, Chotaliya HJ, Modi AD, Parmar AP, Kalele SD. A study of gross postmortem findings in cases of Hanging and Ligature Strangulation. Journal of Indian Academy of Forensic Medicine. 2013;35(1):63-65.
7. Sarangi MP. Ligature marks - In Forensic pathologist's perspective. Journal of Forensic Medicine and Toxicology. 1998;15(1):99-102.

8. Nikolic S, Micic J, Atanasijevic T, Djokic V, Djonic D. Analysis of neck injuries in hanging. Am. J Forensic Med. Pathol. 2003; 24(1):179-182.

9. Ashok Kumar Samanta, Soumya Rajan Nayak. Newer trends in hanging death. Journal of Indian Academy of Forensic Medicine. 2012;34(1):37-39.

10. Vijayakumari N. Suicidal hanging: A prospective study. Journal of Indian Academy of Forensic Medicine. 2011;33(4):353-4. 